\title{
A Method for Service Failure Effects Analysis Based on Customer Satisfaction
}

\author{
Yusuke Kurita $^{1, *}$, Koji Kimita ${ }^{2}$, Kentaro Watanabe $^{3}$, and Yoshiki Shimomura ${ }^{1}$ \\ ${ }^{1}$ Dept. of System Design, Tokyo Metropolitan University, Tokyo, Japan \\ kurita-yusuke@sd.tmu.ac.jp, yoshiki-shimomura@center.tmu.ac.jp \\ ${ }^{2}$ Dept. of Management Science, Tokyo University of Science, Tokyo, Japan \\ kimita@ms.kagu.tus.ac.jp \\ ${ }^{3}$ Center for Service Research, National Institute of Advanced Industrial Science and \\ Technology, Tokyo, Japan \\ kentaro.watanabe@aist.go.jp
}

\begin{abstract}
Recently, the importance of service is widely accepted. Service Engineering that aims to design a service from the engineering viewpoint has been proposed. In order to achieve a successful service, service providers should maintain service quality and always satisfy their customers. To be specific, the provision of highly reliable service is essential. To realize highly reliable services it is important to minimize the occurrence of service failures. This paper proposes a method for analyzing service failure effects in the service design phase. Specifically, we define service failure and propose a procedure to analyze service failure effects with models that are proposed in Service Engineering. The proposed method is verified through its application to a nursing-care service.
\end{abstract}

Keywords: Service reliability, Service failure, Service Engineering.

\section{Introduction}

Recently, customer demands have become more varied due to the maturing of economy. It is difficult to satisfy such customer demands purely with physical products; thus, an approach that combines physical products and intangible services is widely accepted. Manufacturing companies have been making a fundamental shift away from selling only physical products towards providing a combination of products and services. For example, Rolls-Royce is selling energy to an airline, rather than selling engines [1]. Clearly, service is an important aspect of many industries.

Service has been the subject of extensive research in the academic field. Recently, service has been discussed from the engineering or scientific perspective rather than from the perspective of traditional service marketing [2, 3] that focuses on the characteristics of service. For example, service engineering [4] has been proposed from an engineering point of view in Japan and focuses especially on the design of

\footnotetext{
* Corresponding author.
} 
services. In other locations, particularly Europe, product-service systems (PSSs) [5, 6] that aim to provide value by coupling physical products and intangible services have been actively discussed. On the other hand, service science [7] has been proposed in the United States. This aims to create the basis for systematic service innovation.

In general, in order to make a service successful and profitable, service providers need to establish long-term relationships with their customers. That is to say, the provision of highly reliable service that is able to consistently satisfy customers' expectations is important. In the product field, the approach to minimizing product failures for customers is widely accepted as a means of realizing highly reliable products. In order to prevent product failures, it is important to identify potential failures and their causes, and take them into account in the design phase. These processes are also useful apply to services because service is also an artifact created by humans. Failure mode and effects analysis (FMEA) [8] or fault tree analysis (FTA) [9] are recognized as effective engineering methods to support the above processes of failure analysis and are applied in various fields. The service field requires an engineering evaluation against service reliability like FMEA. Although failure effect analyses such as FMEA focus on upper-level functions, it is more important to focus on the influence on customer satisfaction because customers evaluate services subjectively. In addition, the degree of influence on customer satisfaction is different for each customer, even if the kind of service failure is the same. Based on this background, we aim to support analysts who analyze service failure effects in order to determine the priority number of service failures. In this paper, we propose a procedure to analyze service failure effects using the analytic hierarchy process (AHP) [10] and models proposed in service engineering. The AHP is utilized to quantify service failure effects and is explained in the detail in section 2.3.

\section{$2 \quad$ Existing Study}

\subsection{Failure Modes and Effects Analysis}

Failure mode and effects analysis is a systematic method of identifying and preventing product and process problems before they occur. This is focused on preventing defects, enhancing safety, and increasing customer satisfaction [11]. Failure mode and effects analysis is a deductive technique that consists of failure identification for each component, its causes and consequences on the equipment and on the whole system. This analysis proceeds with a table called an FMEA worksheet. Elements of this worksheet are flexible and may be changed according to the subject being analyzed. Table 1 shows an example of an FMEA worksheet.

As mentioned in chapter 1 , this paper focuses on the effects of service failure. In the case of a traditional FMEA, failure effects are not changed. However, in the case of services, failure effects change according to the customer's sense of value. Therefore, the FMEA worksheet should be extended. 
Table 1. An example of FMEA worksheet

\begin{tabular}{|c|c|c|c|c|c|c|c|}
\hline \multirow{2}{*}{ Item } & \multirow{2}{*}{ Function } & \multirow{2}{*}{$\begin{array}{l}\text { Failure } \\
\text { mode }\end{array}$} & \multicolumn{2}{|c|}{ Failure effect } & \multirow{2}{*}{$\begin{array}{l}\text { Occurrence } \\
\text { frequency }\end{array}$} & \multirow{2}{*}{ Critically } & \multirow{2}{*}{ Action } \\
\hline & & & First-order & Second-order & & & \\
\hline
\end{tabular}

\subsection{Service Realization Structure}

Service engineering aims to consolidate the methodology for the representation, design, and evaluation of services. Service is defined as "an activity between a service provider and service receiver to change the state of the receiver" [4] in service engineering. According to this definition, a receiver is satisfied when his/her state changes to a new desirable state. Namely, service design should be based on the desired change in the state of the receiver. The target receiver's state is represented as a set of parameters called receiver state parameter (RSP). In service engineering, a sub-model called a view model is proposed to represent a realization structure for changing an RSP. This model consists of functions and entities. Each function has one or several function parameters (FP) that show the degree of functional expression. Function parameters are associated with attribute parameters (APs), which represent the attributes of entities. Figure 1 presents an example of a view model that describes part of the realization structure of a coffee shop service. As shown in Figure 1, functions are described hierarchically in order to change the RSP.

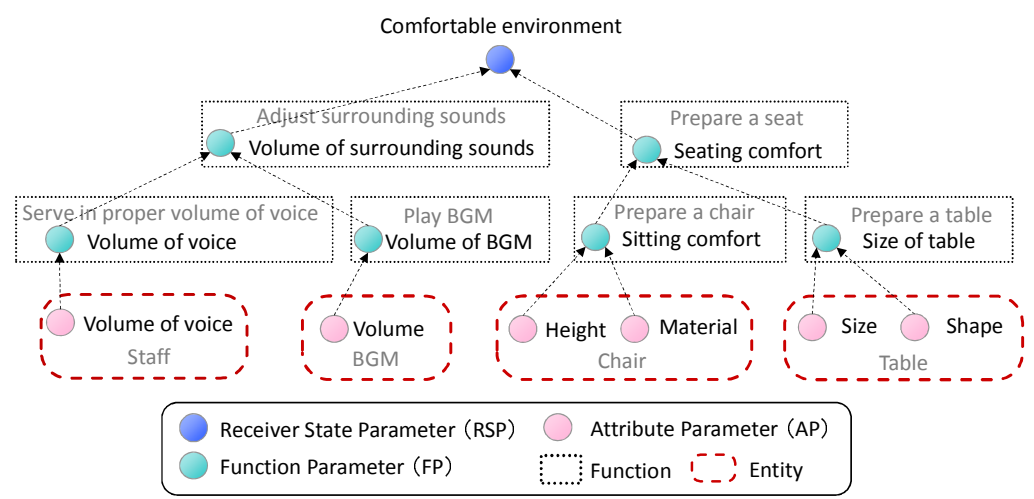

Fig. 1. An example of a view model

\subsection{Analytic Hierarchy Process}

The AHP is a process of deriving relative scales using judgment or data from a standard scale, and performing the subsequent arithmetic operation on such scales to avoid extraneous number crunching. The judgments are given in the form of paired comparisons. One of the uses of a hierarchy is that it allows us to focus judgment separately on each of several properties essential for making a sound decision. The most effective way to concentrate judgment is to take a pair of elements and compare them with respect to a single property, without concern for other properties or other 
elements. This is why paired comparisons in combination with a hierarchical structure are so useful in deriving measurements. This technique is applied to many kinds of cases, and its effectiveness is widely accepted.

In this study, AHP is utilized to quantify service failure effects. Although a view model has hierarchical structure and shows relationship between functions and a customer satisfaction factor, how each function contributes a customer satisfaction factor is not clear. Whereat, this degree of contribution is quantified by AHP.

\section{A Method for Analyzing Service Failure Effects}

\subsection{Outline}

In order to determine the influence of service failure on customer satisfaction, a method for analyzing service failure effects using AHP and models from service engineering has been developed. In the product field, analysts can proceed to analysis using the generalized evaluation axis. However, in the service field, it is difficult to define the evaluation axis compared to the product, since customer evaluation of service is subjective. In this study, the analyst analyzes service failure effects with evaluation axes based on each the customer's sense of value in each category. In addition, service failure effects analysis that considers multiple customer categories is achieved by allocating each customer's value rating by category with respect to intensity of importance in a view model for RSP and FP.

\subsection{A Procedure for Service Failure Effects Analysis}

The proposed method consists of the following four steps:

Step1: Identification of Target Customer Category. In this method, a persona model is constructed to identify target customer categories [12]. A persona model consists of demographic data, such as age and family structure, and psychological data, such as personality and values. Figure 2 shows a persona model for a coffee shop service. The number of persona models in this step is decided based on the cause and purpose of the analysis.
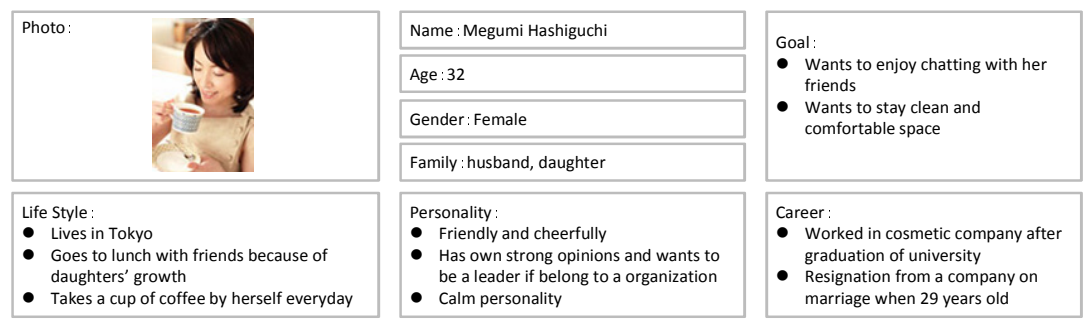

- Really loves chatting with her friends

- Has many friends, so she has many opportunities to go to a coffee shop in order to chat

Fig. 2. A persona model; coffee shop service 
Step 2: Identification of Service Failure. Understanding of service failure differs according to the research field or objective. For example, service marketing explains service failure as an operational miss; it has many discussions on service recovery and how to recover from an operational miss [e.g., 13, 14]. In the reliability engineering field, some researchers define service failure as service defects [15]; others define it as the dissatisfaction that customers experience during the service offering [16]. In this study, the fundamental interpretation of product failure and service failure is essentially the same, because services, like physical products, are also artifacts created by humans. Therefore, services and physical products should not be considered as different things. In this study, the definition of failure by the International Electrotechnical Commission, is applied to service. In this case, the difference between product failure and service failure is in understanding of the word "item" in the IEC's definition. Specifically, an "item" refers to a part of a physical product or system, such as any part, component, or functional unit. Human beings should also be included in the term "item" when we focus on services: a human being is one of the most important elements since the quality of services depends on activity by human beings. Human beings here means not only service providers but also customers, because if the activity of a customer has a negative influence on other customers or a whole service, in general, this case is recognized as a failure. In addition, an entity's functional loss is divided into functional loss that impacts customer satisfaction and functional loss that has no negative influence on customer satisfaction.

Based on the above, in this study a service failure is recognized as an item's failure to perform a function intended by its designer in order to meet a customer requirement. The word "item" here refers to human beings, physical products, systems, services, etc.

To describe a view model, functions that are required to change an RSP, which is identified through the construction of a persona model, are deployed hierarchically; the lowest functions have an entity that is needed to exert the function. An "entity" in a view model corresponds to the term "item" in the definition of service failure in this study. In addition, functions in a view model can be recognized as functions, i.e. the functions designed in order to meet a customer requirement. Therefore, the lowest function's loss can be recognized as a service failure. In this step, service failures are identified by converting the lowest functions in a view model into a negative expression.

Step 3: Quantification of Service Failure Effects on Customer Satisfaction. Service failure effects on customer satisfaction are structured using the described view model in step 2. The importance value, based on each persona's sense of value, is allocated from RSPs to the lowest functions in an integrated view model in order to quantify service failure effects on customer satisfaction. However, it is not easy to quantify the importance of RSPs and functions. Therefore, AHP is adopted in this study in order to determine the importance of each RSP and function. As mentioned in section 3.3, AHP is a structured technique for organizing and analyzing complex decisions. Total importance is 100 in this study. This importance value is allocated from RSPs to the 
lowest functions based on the results of paired comparisons. Here, paired comparison is carried out from each persona viewpoint. The importance of the lowest function is recognized as the degree of influence on RSP, which is a customer satisfaction factor, and is called the effect value on customer satisfaction.

Service designers use the scale shown in Table 2 when pairing comparisons. In addition, Table 3 presents the results of a calculation in the case of three RSPs. In this step, service failure effects on customer satisfaction are quantified by determining the importance of RSP and functions using AHP.

Table 2. The scale for intensity of importance

\begin{tabular}{|c|l|l|}
\hline $\begin{array}{l}\text { Intensity of importance on } \\
\text { an absolute scale }\end{array}$ & Definition & Explanation \\
\hline 1 & Equal importance & $\begin{array}{l}\text { Two activities contribute equally to } \\
\text { the objective }\end{array}$ \\
\hline 3 & $\begin{array}{l}\text { Moderate importance of one } \\
\text { over another }\end{array}$ & $\begin{array}{l}\text { Experience and judgment strongly } \\
\text { favor one activity over another }\end{array}$ \\
\hline 5 & Essential or strong importance & $\begin{array}{l}\text { Experience and judgment strongly } \\
\text { favor one activity over another }\end{array}$ \\
\hline
\end{tabular}

Table 3. An example of paired comparison

\begin{tabular}{|c|c|c|c|c|c|}
\hline & RSP1 & RSP2 & RSP3 & Geometric mean & Importance (total 100) \\
\hline RSP1 & 1 & 3 & 5 & 2.47 & 62 \\
\hline RSP2 & $1 / 3$ & 1 & 5 & 1.19 & 30 \\
\hline RSP3 & $1 / 5$ & $1 / 5$ & 1 & 0.34 & 8 \\
\hline
\end{tabular}

Step 4: Service Failure Effects Analysis. In this step, information obtained from steps 1 through 3 is inserted into a template, as shown in Table 4. First, entities and service failures identified in step 2 are filled out in part (a). Second, identified personas are filled out in part (b). Finally, effect value on customer satisfaction is filled out in part (c). Analysis of service failure effects considering multiple customer categories is realized through the above four steps.

Table 4. A template for service failure effects analysis

\begin{tabular}{|c|c|c|c|}
\hline Entity & Service failure & Persona & Effect value on customer satisfaction \\
\hline \multicolumn{2}{|c|}{ (a) } & (b) & (c) \\
\hline
\end{tabular}

\section{Application}

In this chapter, the proposed method is applied to a nursing-care service. The purpose of this application is to clarify whether service failure effects are quantified appropriately. First, in order to determine target customer categories, two types of persona models were constructed: (1) an elder woman who wants to enjoy living in an elder care facility (see Figure 3); and (2) an elder man who wants to maintain a sense of self-esteem (see Figure 4). 


\begin{tabular}{|c|c|c|}
\hline \multirow[t]{4}{*}{ Photo: } & Name: Kazuko Takahashi & \multirow{4}{*}{$\begin{array}{l}\text { Goal: } \\
\text { - Wants to enjoy living in the elder } \\
\text { care facility } \\
\text { - Wants to make a lot of friends }\end{array}$} \\
\hline & Age: 83 & \\
\hline & Gender: Female & \\
\hline & Family: husband, daughter & \\
\hline $\begin{array}{l}\text { Memo: } \\
\text { - Really loves chatting wit } \\
\text { - Has many friends, so she }\end{array}$ & f conversation & \\
\hline
\end{tabular}

Fig. 3. Persona model of an elder woman

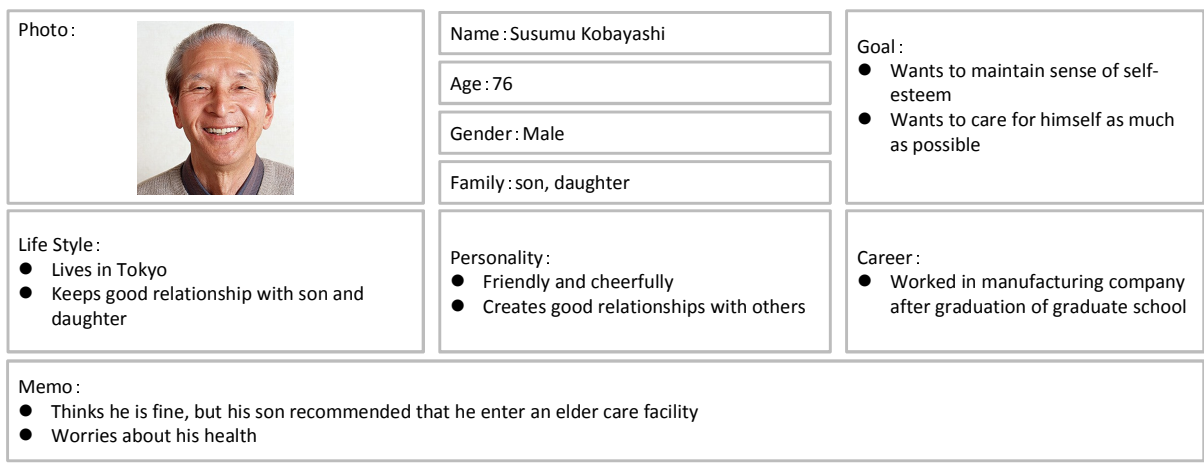

Fig. 4. Persona model of an elder man

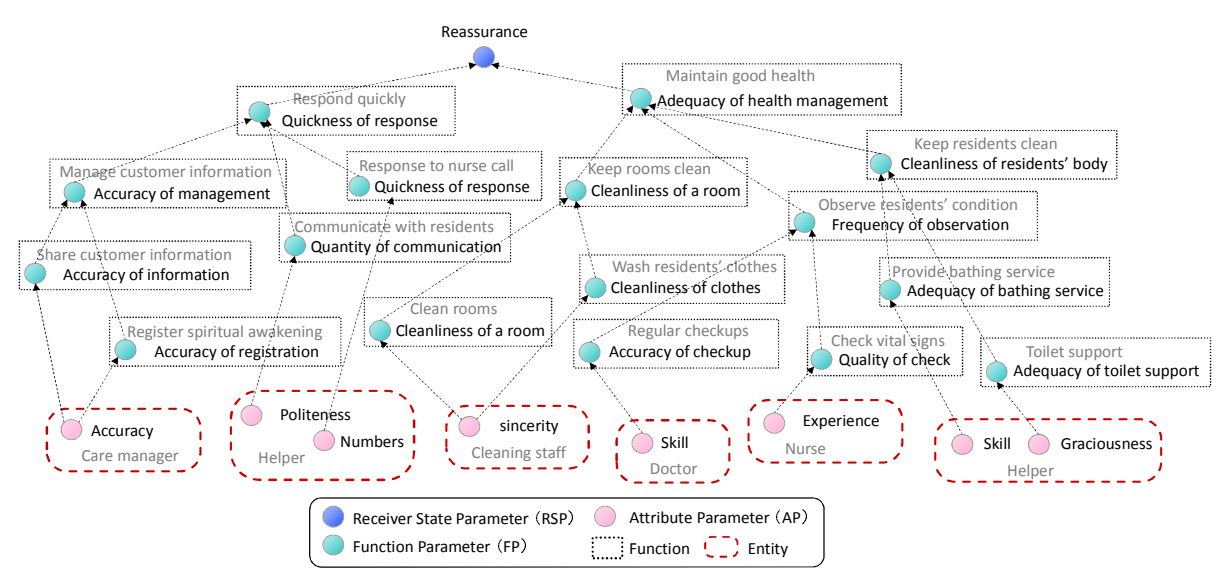

Fig. 5. A view model about nursing-care service

Next a view model is constructed. In this application, "reassurance" is identified as an RSP. Therefore, functions that are needed to change this RSP were deployed and entities were associated with the lowest functions. Figure 5 shows the described view 
model. Service failures were identified by converting the lowest functions in the integrated view model into a negative expression. For example, "share customer information" was converted to "inability to share customer information." The importance value is allocated from RSPs to the lowest functions based on AHP. Finally, identified service failures and their influence value on customer satisfaction were inserted into the template, as shown in Table 4. Table 5 presents the results: the effect value on customer satisfaction is completely different by persona, even if the service failure is the same. For example, the effect value of the service failure "inability to communicate with residents" was 9 in the case of an elder man. On the other hand, in the case of an elder woman, the value was 29 , which is a critical number.

Table 5. Deployment result of service failures and effect value

\begin{tabular}{|c|c|c|c|}
\hline Entity & Service failure & Persona & Effect value \\
\hline \multirow{4}{*}{ Care manager } & \multirow{2}{*}{ Inability to share customer information } & Kazuko Takahashi & 5.2 \\
\hline & & Susumu Kobayashi & 10.1 \\
\hline & \multirow{2}{*}{ Inability to register spiritual awakening } & Kazuko Takahashi & 1.8 \\
\hline & & Susumu Kobayashi & 3.4 \\
\hline \multirow{8}{*}{ Helper } & \multirow{2}{*}{ Inability to communicate with residents } & Kazuko Takahashi & 29.0 \\
\hline & & Susumu Kobayashi & 9.0 \\
\hline & \multirow{2}{*}{ Inability to respond to nurse call } & Kazuko Takahashi & 14.0 \\
\hline & & Susumu Kobayashi & 27.5 \\
\hline & \multirow{2}{*}{ Inability to provide bathing service } & Kazuko Takahashi & 19.5 \\
\hline & & Susumu Kobayashi & 2.3 \\
\hline & \multirow{2}{*}{ Inability to conduct toilet support } & Kazuko Takahashi & 6.5 \\
\hline & & Susumu Kobayashi & 6.7 \\
\hline \multirow{4}{*}{ Cleaning staff } & \multirow{2}{*}{ Inability to clean a room } & Kazuko Takahashi & 6.0 \\
\hline & & Susumu Kobayashi & 6.8 \\
\hline & \multirow{2}{*}{ Inability to wash residents' clothes } & Kazuko Takahashi & 6.0 \\
\hline & & Susumu Kobayashi & 6.7 \\
\hline \multirow{2}{*}{ Doctor } & \multirow{2}{*}{ Inability to conduct regular checkups } & Kazuko Takahashi & 3.0 \\
\hline & & Susumu Kobayashi & 20.6 \\
\hline \multirow{2}{*}{ Nurse } & \multirow{2}{*}{ Inability to check vital signs } & Kazuko Takahashi & 9.0 \\
\hline & & Susumu Kobayashi & 6.9 \\
\hline
\end{tabular}

\section{Discussion}

As shown in Table 5, even if the service failure is the same, its effect on customer satisfaction differs by persona. For example, the service failure "inability to communicate with residents" was the most critical failure for the persona of an elder woman, since she places great value on conversation, as shown in Figure 3. On the other hand, for the persona of an elder man, "inability to respond to nurse call" was the most critical failure, since he worries about his health, as shown in Figure 4. That is to say, the proposed method can reflect each persona's characteristics in the analysis results. Therefore, analysis of service failure effects considering multiple customer categories is achieved. 
In this paper, paired comparison is based on a three-level scale, as shown in Table 2 , in order to decrease the amount of work. Specifically, if the scale is different on one level, the allocation result is quite different. Therefore, we must reconsider the number of levels within the scales. For example, Saaty [10] proposes a five-level scale, as shown in Table 6. In addition, this paper only focuses on two values: service failure or no service failure. However, the degree of functional loss should also be considered. If we can identify the relationship between the degree of functional loss and the influence value on customer satisfaction, we expect to realize a refined analysis of service failure effects.

Table 6. The fundamental scale proposed by Saaty [10]

\begin{tabular}{|c|l|l|}
\hline $\begin{array}{c}\text { Intensity of } \\
\text { importance }\end{array}$ & \multicolumn{1}{|c|}{ Definition } & \multicolumn{1}{c|}{ Explanation } \\
\hline 1 & Equal importance & Two activities contribute equally to the objective \\
\hline 3 & $\begin{array}{l}\text { Moderate importance of one over } \\
\text { another }\end{array}$ & $\begin{array}{l}\text { Experience and judgment strongly favor one } \\
\text { activity over another }\end{array}$ \\
\hline 5 & Essential or strong importance & $\begin{array}{l}\text { Experience and judgment strongly favor one } \\
\text { activity over another }\end{array}$ \\
\hline 7 & Very strong importance & $\begin{array}{l}\text { An activity is strongly favored and its dominance } \\
\text { demonstrated in practice }\end{array}$ \\
\hline 9 & Extreme importance & $\begin{array}{l}\text { The evidence favoring one activity over another } \\
\text { is of the highest possible order of affirmation }\end{array}$ \\
\hline $2,4,6,8$ & $\begin{array}{l}\text { Intermediate values between the two } \\
\text { adjacent judgments }\end{array}$ & When compromise is needed \\
\hline
\end{tabular}

\section{Conclusion}

The purpose of this paper is to quantify the effects of service failure on customer satisfaction, in order to realize highly reliable services. To achieve this purpose, we proposed a method of analyzing service failure effects. Specifically, we proposed a procedure to analyze service failure effects using AHP and models proposed in service engineering. We applied the proposed method to a nursing-care service. The result of this application showed a realization of service failure analysis considering multiple customer categories. Future works will reconsider the number of levels in the multi-level scale in order to improve the quality of the results. In addition, the degree of functional loss should be considered in order to realize a more exhaustive analysis of service failure effects.

\section{References}

1. Harrison, A.: Design for service -harmonizing product design with a services strategy. In: Proceedings of GT 2006, ASME Turbo Expo 2006: Power for Land, Sea and Air, Barcelona, Spain (2006)

2. Parasuraman, A., Zeithaml, V.A., Berry, L.L.: A conceptual model of service quality and implications for further research. Journal of Marketing 49, 45-50 (1985)

3. Parasuraman, A., Zeithaml, V.A., Berry, L.L.: Servqual: A multiple item scale for measuring consumer perceptions of service quality. Journal of Retailing, 22-40 (1988) 
4. Arai, T., Shimomura, Y.: Proposal of Service CAD System: A Tool for Service Engineering. Annals of the CIRP 53(1), 397-400 (2004)

5. Tukker, A., Tischner, U.: Product-services as a research field: past, present and future. Reflections from a decade of research. Journal of Cleaner Production 14(17), 1552-1556 (2006)

6. Morelli, N.: Product-Service Systems: a Perspective Shift for Designers. A Case Study The Design of a Telecentre-, Design Studies 24, 73-99 (2003)

7. Maglio, P.P., Kreulen, J., Srinivasan, S., Spohrer, J.: Service systems, service scientists, SSME, and innovation. Communications of the ACM 49(7), 81-85 (2006)

8. IEC 60812, 2edn. Analysis technique for system reliability -Procedure for failure mode effects analysis (FMEA) (2006)

9. IEC 61025,2 edn. Analysis technique for system reliability -Procedure for fault tree analysis (FTA) (2006)

10. Saaty, T.: How to make a decision: The Analytic Hierarchy Process. Journal of Operational Research 48, 9-26 (1990)

11. Robin, T.M., Raymond, J.M., Michael, R.B.: The Basics of FMEA, 2nd edn. Productivity Press (1996)

12. Hosono, S., Hasegawa, M., Hara, T., Shimomura, Y., Arai, T.: A Methodology of Personacentric Service Design. In: Proceedings of CIRP Design Conference 2009, pp. 541-546 (2009)

13. Tax, S.S., Brown, S.W.: Recovering and Learning from Service Failure. Slone Management Review, 75-88 (Fall 1998)

14. Kelly, S.W., Hoffman, K.D., Davis, M.K.: A Typology of Retail Failures and Recoveries. Journal of Retailing 64(4), 429-452 (1993)

15. Masuda, A., Iwase, T., Suzuki, K.: Development of Three Element FMEA Considering the Interaction between Human, Environment and Equipment for Reliability and Safe Analysis. The Japanese Society for Quality Control (JSQC) 24(1), 122-135 (1999) (in Japanese)

16. Yokoyama, S.: FTA for Service Reliability Evaluation. Journal of Reliability Engineering Association of Japan (REAJ) 34(1), 24-29 (2009) (in Japanese) 